\title{
Naturaleza muerta y vanitas en la poesía española contemporánea
}

\author{
Still life and vanitas in contemporary \\ Spanish poetry \\ MARÍA EMA LLORENTE \\ Universidad Autónoma del Estado de Morelos (UAEM) \\ emmall@uaem.mx
}

Recibido: 26-03-2012

Aceptado: 12-01-2013

\section{Resumen}

Este artículo se centra en el análisis de determinados poemas españoles contemporáneos que recrean el tema de los bodegones o naturalezas muertas, en su variante específica de vanitas. Aunque estos poemas pueden insertarse dentro de la tradición literaria de la poesía elegíaca, su escritura sigue más de cerca la tradición pictórica de bodegones, desarrollada especialmente durante la época barroca. Esta preeminencia de lo visual puede apreciarse en los textos en la presencia de rasgos como la descripción detallada y precisa de los objetos, la representación plástica de su degeneración o su corrupción y el procedimiento retórico de la écfrasis. Partiendo de esta idea, el artículo intenta explicar o justificar, en primer lugar, las posibles causas de esta recurrencia temática en la poesía española actual, para después analizar el conjunto de estos poemas en sus características fundamentales.

Palabras clave: contraste temporal, corrupción, elegía, écfrasis, narrativización, enunciación, deixis.

\section{Abstract}

This article focuses on the analysis of various contemporary Spanish poems that recreate the theme of Still Lifes, in the specific variant of Vanitas. Although these poems can be inserted within the literary tradition of elegiac poetry, they follow 
more closely the pictorial tradition of Still Lifes, especially developed during the baroque era. These specific poems highlight the visual aspects of the Still Lifes represented, using detailed and accurate descriptions of the objects and the procedure of rhetorical ecfrasis. For example, the descriptions are so vivid one could imagine the degeneration or the corruption of the objects. Based on this idea, the article attempts to explain or justify the possible causes of this thematic recurrence in the current Spanish poetry, and then analyzes the selection of these poems in its fundamental characteristics.

Keywords: temporal contrast, corruption, elegy, ecfrasis, narrativization, enunciation, deixis.

En la poesía española contemporánea, la publicada a partir de la década de los años 80 y hasta la actualidad, puede apreciarse un interés recurrente en distintos autores por el tratamiento poético del tema de los bodegones, naturalezas muertas y vanitas. Esta inclinación puede detectarse, en primer lugar, en algunos de los títulos de estos poemas, que aluden tanto de manera general como específica a las composiciones pictóricas de este género. Es el caso, por ejemplo, de los numerosos textos titulados con la palabra «Bodegón», entre los que se encuentran los de Carmen Pallarés ${ }^{1}$, Guadalupe Grande ${ }^{2}$, Vicente Valero ${ }^{3}$, Juan Manuel Bonet ${ }^{4}$ y Rafael Espejo5; o, directamente con el nombre «Vanitas», como el poema de Javier Rodríguez Marcos ${ }^{6}$. Pero también podrían incluirse en este grupo poemas cuyos títulos aluden a estas composiciones de una manera indirecta o menos evidente, como por ejemplo, «La manzana», de José Ramón Barat7; «Un vaso con anémonas», de Eloy Sánchez Rosillo8; y «Variación sobre una metáfora barroca», de Vicente Gallego'.

\footnotetext{
1 Pallarés, C., «Bodegón», en Benegas, N. y Munárriz, J., (eds.), Ellas tienen la palabra. Dos décadas de poesía española, Madrid, Hiperión, 1998, p. 117.

2 Grande, G., «Bodegón», en Benegas y Munárriz (eds.) 1998, op. cit. (nota 1), pp. 606-607.

3 Valero, V., «Bodegón», en Cano, J., (ed.), Poesía española reciente (1980-2000), Madrid, Cátedra, 2002 , p. 319.

${ }^{4}$ Bonet, J. M., «Bodegón», en Cano (ed.) 2002, op. cit. (nota 3), pp. 128-129.

5 Espejo, R., «Bodegón», en Munárriz, J., (ed.), Veinticinco poetas españoles jóvenes. Antología, Madrid, Hiperión, 2003, p. 136; y «Bodegón cubista», en Cano (ed.) 2002, op. cit. (nota 3), pp. 319320.

6 Rodríguez, J., «Vanitas», en García, J. L., (ed.), La Generación del 99, Oviedo, Nobel, 1999, pp. 353 354.

7 Barat, J. R., «La manzana», Piedra primaria, Gijón, Ateneo Jovellanos, 2004, p. 18.

8 Sánchez, E., «Un vaso con anémonas», Elegías, Madrid, Trieste, 1984, p. 24.

9 Gallego, V., «Variación sobre una metáfora barroca», en Mainer, J. C. (ed.), El último tercio del siglo (1968-1998). Antología consultada de la poesía española, Madrid, Visor, 1999, pp. 792-793.
} 
El interés que muestran éstos y otros poemas por el tema artístico de las naturalezas muertas va más allá de la simple alusión que aparece en el título, ya que en ellos se realiza una recuperación y una reelaboración de las principales ideas y tópicos asociados comúnmente a este género, al tiempo que se ofrece una versión poética del mismo.

Creo que la abundancia de este tipo de poemas en la poesía española actual puede explicarse por dos causas o motivaciones diferentes.

En primer lugar, por la tendencia general de la poesía contemporánea hacia lo visual, lo gráfico y lo plástico. En este sentido, Domingo Sánchez-Mesa, en su revisión de tendencias o «constantes fundamentales» de la producción poética contemporánea, señala como una característica de esta escritura la aparición de «nuevas formas de visualidad», que hacen que esta poesía, inserta en un paradigma dominado más por la imagen que por el logos, tenga más presente que nunca el referente plástico:

Sería absurdo pensar que la palabra poética no acusara este «giro pictórico» (...), ya que siempre ha estado relacionada con la «imagen», desde la literalidad del jeroglífico o el caligrama, a la metáfora y la écfrasis. Para la mirada de la voz poética y sus impulsos ekfrásticos, el referente plástico sigue siendo importante de forma explícita, siendo incluso más importante la pintura o la escultura que el cine. ${ }^{10}$

Este giro pictórico al que alude Sánchez-Mesa, retomando la expresión de William J. T. Mitchell11, puede apreciarse en los textos tanto en esos «impulsos ekfrásticos», según los cuales el poema se presenta como una descripción lingüística de una obra pictórica, como en determinado uso del color, la adjetivación y la sinestesia. También en las referencias a determinados artistas y obras, cuyos nombres aparecen, de forma más o menos explícita en muchos de estos poemas, así como en la adaptación o recreación de géneros o subgéneros artísticos como el retrato, el paisaje o el bodegón, como ocurre en este caso.

Además de en estos elementos, el giro hacia lo pictórico de la poesía contemporánea puede advertirse también en el aumento de trabajos críticos dedicados a las relaciones entre poesía y pintura, como son, por ejemplo, los de P. Standish, Línea y color: desde la pintura a la poesía12; A. Domínguez Leiva, «Hacia una tipología de claves plásticas en la poesía española (1960-1980)»13; y F. Gutiérrez Carbajo,

10 Sánchez-Mesa, D., (ed.), Cambio de siglo: Antología de la poesía española 1990-2007, Madrid, Hiperión, 2007, p. 55.

11 Mitchell, W. J. T., «El giro pictorial», Teoría de la imagen. Ensayos sobre representación visual, Madrid, Akal, 2009, pp. 19-38.

12 Standish, P., Linea y color: desde la pintura a la poesía, Madrid, Vervuert, 1999.

13 Domínguez Leiva, A., «Hacia una tipología de claves plásticas en la poesía española (1960-1980)», Studi Ispanici, 3 (2000), Pisa-Roma, Fabrizio Serra, pp. 205-215. 
«La forma y el color de las palabras: algunos ejemplos de la poesía española contemporánea» ${ }^{14}$, por citar sólo algunos de ellos.

En segundo lugar, además de la relación que guarda esta poesía con lo visual, considero que la recreación poética o reescritura de naturalezas muertas en la poesía más reciente tiene que ver con la situación de malestar e incertidumbre del hombre contemporáneo y con los cuestionamientos existenciales derivados de la posmodernidad, que renuevan la preocupación por el tema del paso del tiempo y sus consecuencias en el individuo. Como señala José María Ferri Coll, la conciencia de la temporalidad y la fugacidad de las cosas parece intensificarse durante los periodos finiseculares, acentuando las sensaciones de pérdida y desengaño. Acorde con esta idea, según el mismo crítico indica, la poesía española de las tres últimas décadas del siglo XX poetiza los temas relativos a la fugacidad del tiempo, moldeando o adaptando el tópico antiguo a las preocupaciones propias de la época actual ${ }^{15}$.

Esta preocupación por el paso del tiempo hace que la poesía contemporánea adquiera, en muchas ocasiones, el tono elegíaco del lamento por el pasado y por la pérdida, que tampoco encuentra consuelo en el futuro y en el inevitable final que éste depara, tal como señala José Enrique Martínez:

La poesía actual se impregna con frecuencia de vagos lamentos elegíacos. Una mirada melancólica se extiende sobre las cosas y sobre la memoria del pasado. El poeta da cuenta de la fugacidad de la belleza, de la ilusión, de la juventud. El paso del tiempo -tema central en esta tendencia- deja una pátina de desengaño. El dolorido sentir mueve la expresión del amor, del tiempo y de la naturaleza. Y si se mira hacia el futuro se adelanta la labor prevista del tiempo y de la muerte.16

La idea de la tendencia o el tono elegíaco de esta poesía se relaciona ya de manera explícita con el tema de la vanitas en la formulación final que cierra el mencionado estudio de José María Ferri Coll: «En el otoño del siglo XX, uno de los motivos más recurrentes en la poesía española es el sentimiento de la vanitas, del que se desprende una nota de nihilismo» ${ }^{17}$.

Todas estas sensaciones de desengaño, pesimismo, preocupación por el tiempo y por la muerte acercan, en algunos aspectos, parte de la poesía española contemporánea a la poesía del Barroco, con la que guarda algunas relaciones y similitudes, tal como ya ha sido advertido por la crítica ${ }^{18}$.

14 Gutiérrez Carbajo, F., «La forma y el color de las palabras: algunos ejemplos de la poesía española contemporánea», Studi Ispanici, 3 (2000), Pisa-Roma, Fabrizio Serra, pp. 217-229.

15 Ferri Coll, J. M., «Itálica abolida: Una lección de vanitas en la poesía española contemporánea», Anales de Literatura Española, 17 (2004), Alicante, Universidad de Alicante, p. 36.

16 Martínez, J. E., (ed.), Antología de poesía española (1975-1995), Madrid, Castalia, 1997, p. 33.

17 Ferri Coll 2004, op. cit. (nota 15), p. 46.

18 En relación con este tema, véase Martín-Estudillo, L., La mirada elíptica: el trasfondo barroco de la poesía española contemporánea, Madrid, Visor, 2007. 
También Julia Castillo, autora de un libro titulado precisamente Poemas de la imaginación barroca, admite, en la introducción, la consonancia de su poesía con la poesía del Siglo de Oro, algo que ella atribuye a la presencia de intereses y características comunes en ambas producciones, entre las que se encuentra la ya citada «lucha por lo pictórico»:

En algunos de los presentes poemas, en efecto, una imagen producto de nuestro Siglo de Oro ha prestado a mi escritura su emblemática presencia, su síntesis de temas inmutables de la poesía, como son el tiempo, la libertad, o el simbolismo de la muerte. (...) La capacidad simbólica de la visión, la lucha por lo «pictórico», la tendencia a lo vario, y la voluntad de síntesis, propias del barroco, no dejan de serlo, salvando las diferencias, también en nuestra época. 19

El género mismo del bodegón, la naturaleza muerta o la vanitas es un género que alcanza su plenitud durante la época barroca, y la recuperación o recreación de estos tópicos y temas en la actualidad incluye, muchas veces, referencias intertextuales, tanto poéticas como pictóricas, a obras barrocas concretas, en un claro ejemplo de esa tendencia a revisitar la tradición de las poéticas posmodernas y contemporáneas.

En lo que respecta a la poesía, esta tendencia intertextual puede verse, por ejemplo, en las referencias directas a la poesía de Quevedo, algunos de cuyos versos funcionan como verdaderos estandartes o emblemas del sentimiento general del desengaño de toda una época. Estas referencias aparecen, entre otros, en el poema «Todo tendrá sentido», que inicia el poemario Elegías, de Eloy Sánchez Rosillo ${ }^{20}$. Este texto alude al conocido verso del poema de Quevedo «Amor constante más allá de la muerte», en el que, a pesar del paso del tiempo, y gracias al efecto del amor, el alma, las venas, las médulas y el cuerpo todo del hablante «serán ceniza, más tendrá sentido». También el poema «Recuerda», de Rosa Romojaro, que termina calificando los objetos cotidianos como «recados de la muerte», remite al «Salmo XVII» de Quevedo, «Miré los muros de la Patria mía», que concluye con la misma idea: «Y no hallé cosa en que poner los ojos/ que no fuese recuerdo de la muerte» 21 .

Pero las alusiones a la poesía barroca en la época contemporánea no se limitan a este único autor, sino que se extienden a otros poetas barrocos, en composiciones que llegan a ser auténticas glosas de los poemas anteriores, como en el caso de los poemas de Julia Castillo «A la dama cuyas cenizas trajo por arenas su amado en un reloj», y «A Francisco López de Zárate, en su soneto a una dama retratada con una

19 Castillo, J., Poemas de la imaginación barroca, Santander, La isla de los ratones, 1980, pp. 11 y 14. El entrecomillado es del original.

20 Sánchez 1984, op. cit., (nota 7), p. 11.

21 Blecua, J. M. (ed.), Obra Poética, Madrid, Castalia, 1999, vol. I, pp. 184-185. 
calavera en la mano, y esta letra, sicut flos» 22 , que se presentan, según declaración de la propia autora, como una reescritura de los poemas del autor mencionado.

En lo que a las referencias pictóricas se refiere, la recreación poética del género de la vanitas remite a toda la serie de elementos y símbolos que constituyen la base conceptual de estas composiciones, y que aparecen mencionados en los textos de forma explícita, como son, por ejemplo, las calaveras, los relojes, los libros, los instrumentos musicales, o las flores y frutos, que forman parte ya de un imaginario cultural colectivo y de una tradición cuyo reconocimiento contribuye a la correcta comprensión e interpretación de los poemas por parte de los receptores 23 .

Una vez señalada esta tendencia en la poesía española actual y apuntadas dos de sus posibles causas o motivaciones se hace necesario, antes de entrar en el análisis concreto de los poemas y su caracterización, especificar qué se entiende por vanitas o naturaleza muerta, y cómo puede o debe concebirse este término en relación con la poesía.

Terminológicamente, la expresión «naturaleza muerta», calco o copia de la expresión francesa, no aparece hasta el siglo XIX. Hasta ese momento se utilizaba de manera general el término «bodegón», documentado desde finales del s. XVI y de uso general hasta el s. XVIII ${ }^{24}$. Con este término se designaban en un principio las representaciones pictóricas de alimentos y cosas de comer y beber, pues, según

22 Castillo 1980, op. cit. (nota 19), pp. 36-39.

23 En relación con la presencia de estos elementos en la literatura española del Barroco y su interpretación, véanse Andrés, R., (ed.), Tiempo y caída, Barcelona, Quaderns Crema, 1994, 2 vols; y Wardropper, B., "Vanitas Poetry in the Spanish Baroque», en Dutton, B. y Roncero, V. (eds.), Busquemos otros montes y otros ríos. Estudios de literatura española del Siglo de Oro dedicados a Elias L. Rivers, Madrid, Castalia, 1992, pp. 282-291. Para el caso pictórico puede consultarse Gállego, J., Visión y símbolos en la pintura española del Siglo de Oro, Madrid, Aguilar, 1972, pp. 232-259.

24 Aunque el término bodegón se documenta desde finales del siglo XVI y el género como tal adquiere importancia a partir de esta fecha, existen composiciones pictóricas semejantes en periodos anteriores. Alberto Corazón menciona como antecedentes del bodegón las pinturas egipcias: «Parece que el bodegón tiene su inicio iconográfico en Egipto. Los pueblos primitivos siempre han dejado comida a sus muertos. Ya en el neolítico hay cántaros y platos en las tumbas, una ayuda para el inicio del último asombroso viaje que emprendían. Son los egipcios los que, ante exigencias que desconocemos, deciden pintar la comida en la pared de la tumba, en lugar de limitarse a depositarla. Afirmaban que gracias a esas pinturas el ka, el alma, podría vivir hasta la aparición de Osiris». Corazón, A., El bodegón habla de otras cosas, Madrid, Antonio Machado, 2005, p. 21. Por su parte, en el mundo clásico griego y latino existían también representaciones pictóricas de distintos tipos de comida, denominadas xenion o xenia, palabra que hace alusión a los regalos que el dueño de la casa ofrece a sus visitantes. Norman Bryson define y explica estas composiciones de la siguiente manera: «los romanos poseían una categoría pictórica muy semejante a lo que más tarde se llamaría "naturaleza muerta": xenia. Las obras que sobreviven cumplen con las subsiguientes definiciones de esta rama de la pintura: representan still-stehende Sache, cosas quietas, nature reposée, objetos en reposo; cosas tales como fruta, cestos de flores, hogazas de pan, aguamaniles, jarras, platos, pescado, marisco, caza -el repertorio familiar del género posterior-». Bryson, N., Volver a mirar. Cuatro ensayos sobre la pintura de naturalezas muertas, Madrid, Alianza, 2005, p. 19. 
la etimología de la palabra recogida en el diccionario de Covarrubias, de 1611, el bodegón es: «El sótano o portal bajo, dentro del cual está la bodega, adonde el que no tiene quien le guise la comida la halla allí aderezada y juntamente la bebida, de manera que se dijo de bodega» 25 . A esta primera restricción o limitación del contenido se fueron añadiendo después otros elementos, como diferentes tipos de alimentos, animales de caza y objetos inanimados como armas, vidrios y barros, pájaros, etc. 26

Desde el origen de este término, a finales del s. XVI, y durante todo el s. XVII, este género fue considerado un género menor, de mal gusto e incluso ordinario, ya que cuando no evadía directamente la pintura de figuras, considerada como superior, se complacía en la representación de lo cotidiano y de la gente del pueblo, en una época en la que el arte estaba reservado a la nobleza y los intelectuales 27 . De hecho, su origen pictórico suele atribuirse al cuadro «Cesta de frutas» (c. 1596), de Caravaggio, pintor que imitaba las cosas viles, eligiendo o prefiriendo para sus representaciones «lo sucio y lo deforme», y que se decantaba para sus pinturas de «cabezas» por temas y modelos como: «la plebe, la gente vulgar, las tabernas, los mendigos y pordioseros» ${ }^{28}$.

A pesar de que la intención inicial de las pinturas de bodegones o naturaleza muertas era la imitación de lo visible o de la naturaleza, muchos de sus elementos fueron tomados como alegóricos o simbólicos, en una sociedad y una época impregnada de la presencia de lo religioso y movida por la predicación eclesiástica ${ }^{29}$. De esta forma, y según las intenciones e interpretaciones básicas de las diferentes obras que pueden englobarse dentro de esta categoría, puede hablarse de tres tipos o variantes del bodegón, que existen desde sus comienzos y hasta bien entrado el siglo XVII. Por un lado, y respondiendo a esa primera preocupación o intención de imitación de la naturaleza, se encuentran las composiciones que se denominan también trompe-l'oeil, en las que el artista pone a prueba su virtuosismo, tratando de engañar al espectador con cuadros de un realismo extremo ${ }^{30}$.

25 De Covarrubias, S., Tesoro de la lengua castellana o española, Madrid, Iberoamericana-Vervuert, 2006, p. 338.

26 Prieto, M., ¿Naturaleza muerta o bodegón?, Barcelona, CODECO, 1987, p. 21.

27 Norman Bryson comenta a este respecto: «Siempre ha sido el género del que menos se ha teorizado, y cuando las academias que elaboraron los primeros informes teóricos sobre la pintura empezaron a mencionarlo, lo hicieron despectivamente: la naturaleza muerta siempre estaba en el nivel más bajo de la jerarquía, indigna del tipo de atención superior que se reservaba a la pintura histórica o la grande manière». Bryson 2005, op. cit. (nota 24), p. 10.

28 Prieto 1987, op. cit. (nota 26), p. 24.

29 Ibidem, p. 15.

30 En relación con este tipo de composiciones y su ilusión de realismo es famosa la anécdota narrada en la Historia natural de Plinio, el viejo, sobre la contienda entre los pintores Parrasio y Zeuxis hacia el año 400 a. C., que Lily Litvak resume de la siguiente manera: «Zeuxis había pintado en una pared un racimo de uvas que se veían tan naturales, que los pájaros volaron hacia ellas para picotearlas. 
Además de este tipo de recreaciones, existe lo que podría denominarse bodegón «simbólico», en el que se representan los cinco sentidos, a veces unidos a símbolos religiosos o elementos de la naturaleza. Esta cualidad alegórica de algunos bodegones permite compararlos, tal como ha hecho Alberto Corazón, con los emblemas y con su intención moralizante, lo que otorga a estas imágenes la posibilidad de una doble interpretación. En un primer nivel, la contemplación de la representación de objetos de la naturaleza que muestra la pintura proporciona al gran público una apreciación o un disfrute puramente estético, al que las personas de cultura humanista son capaces de añadir, en un segundo nivel interpretativo, una comprensión alegórica, posibilitada gracias al descubrimiento de reflexiones morales, alusiones políticas o dogmas religiosos en la imagen ${ }^{31}$.

Y por último, el tipo de bodegón o naturaleza muerta que más interesa para este trabajo es el denominado vanitas, que puede verse como una particularización del anterior, y que Montserrat Prieto define de la siguiente forma:

un tipo de bodegón llamado vanitas, destinado a recordar la fugacidad e instrascendencia de la vida, con un trasfondo religioso representado por el cráneo de una calavera como símbolo de la muerte y del más allá, un candelabro con una vela encendida y un reloj de arena, como imágenes de la fragilidad y la limitación de la vida, además de monedas, libros, flores, mariposas, etc. 32

Aunque las denominaciones de vanitas o naturaleza muerta aluden comúnmente creaciones pictóricas ${ }^{33}$, puede hablarse también de composiciones de vanitas poética en cuanto construcciones textuales en las que están presentes los mismos temas y tópicos que en la pintura de este género, como son, por ejemplo, el vanitas vanitatum, el tempus fugit o la brevitas, que adquieren especial importancia y desarrollo en la poesía del siglo XVII34.

Parrasio pintó entonces una cortina, real hasta tal punto, que Zeuxis, encantado con el veredicto de las aves, pidió a su rival que la descorriera y mostrara la pintura. Al descubrir su error, reconoció que el premio pertenecía a su contrincante, admitiendo francamente que él, Zeuxis, había engañado sólo a los animales, mientras que Parrasio había engañado a un pintor». Litvak, L., «Una naturaleza muerta. Rubén Darío derrota a Zeuxis y a Parrasio», Imágenes y textos. Estudios sobre literatura y pintura 1849-1936, Ámsterdam-Atlanta, Rodopi, 1998, pp. 35-36.

31 Corazón 2005, op. cit. (nota 24), p. 53.

32 Prieto 1987, op. cit. (nota, 26), p. 31.

33 En este sentido, Bruce Wardropper apunta que el arte que desarrolla el tema o el tópico in ictu oculi ha sido denominado por los historiadores «vanitas painting», término que él hace extensivo al de «vanitas art», aduciendo que este tipo de representaciones puede adoptar otras formas diferentes a la pintura, entre las que se encuentran, el dibujo y la escritura. Wardropper 1992, op. cit. (nota 23), p. 282.

34 Dámaso Alonso, comentado el poema gongorino «Alegoría de la brevedad de las cosas humanas», en el que aparece el tópico de brevitas o in ictu oculi, lo declara como uno de los temas predilectos del barroco y señala que este tema aparece «lo mismo en pintura (Valdés Leal, etcétera) que en poesía». Alonso, D., Góngora y el «Polifemo». Antología de Góngora, Madrid, Gredos, 1967, vol. 2, p. 130. 
Según esto, puede establecerse una relación estrecha entre la pintura y la escritura, pues existen muchos cuadros que surgen motivados por textos literarios y viceversa.

Alberto Veca señala, en este sentido, que las composiciones pictóricas de vanitas tienen, en general, un marcado aspecto literario, pues retoman en su representación numerosos elementos que pertenecen a un imaginario cultural que proviene, en su mayoría, del Antiguo Testamento ${ }^{35}$. La misma palabra que da nombre a todo el género, vanitas o vanidad, está inspirada en las palabras del Eclesiastés (I. 2): «Vanidad de vanidades y todo vanidad» 36 .

De la misma forma, muchos otros tópicos relacionados con esta idea tienen la misma procedencia. Por ejemplo, el tema de la conversión o el retorno del hombre a las cenizas, incontablemente tratado en este género, aparece ya en el libro del Génesis (III. 19). El lema o el motivo del in ictu oculi, que Valdés Leal utiliza como título para uno de sus más famosos cuadros de vanitas, pertenece a la «Epístola de San Pablo a los Corintios» (XV. 52): «En un abrir y cerrar de ojos, los muertos resucitarán incorruptibles». En Isaías se encuentra ya la comparación o la identificación de la carne con la hierba y de los bienes materiales con la flor del campo, en lo que constituye el tópico denominado sicut flos (XL. 6), recreado en el poema de Francisco López de Zárate, «A un retrato de una dama, con una calavera en la mano, y esta letra, sicut flos» ${ }^{37}$, y glosado, a su vez, por Julia Castillo, como se comentó más arriba.

Además de estas referencias al Antiguo Testamento, Emilio Orozco señala también, como precursores textuales, las producciones literarias de la época clásica y del Renacimiento, de acuerdo con la idea, defendida por este autor, de que lo textual o lo poético precede, por lo general, a lo pictórico en la historia de las manifestaciones artísticas:

En el cambio del punto de vista, en la aproximación y morosidad anotadora del detalle de los objetos, frutas y flores - distinta del primitivo, aunque con cierta relación-, precede a la plástica la poesía. Ello es general siempre en la innovación artística. El barroquismo se ha impuesto en lo literario cuando el clasicismo perdura aún en la plástica. Así, el recreo ante la belleza de la flor, el florero y hasta el bodegón, se da antes en la poesía. 38

En el caso literario, además, este tipo de poemas de vanitas o naturaleza muerta podría incluirse en el género más amplio de la poesía elegíaca, que cuenta con

\footnotetext{
35 Wardropper 1992, op. cit. (nota 23), p. 283.

36 Gállego 1972, op. cit. (nota 23), p. 243.

37 Wardropper 1992, op. cit. (nota 23), pp. 284 y 289.

38 Orozco, E., Temas del Barroco de poesía y pintura, Granada, Universidad de Granada, 1989, p. 20.
} 
una larga tradición desde sus orígenes en la poesía griega hasta la actualidad, y que puede entenderse tanto en su acepción restringida de llanto por la muerte de algún individuo, ya sea conocido o público, como en su significado general de lamento por la pérdida de elementos más abstractos como la infancia, la juventud, el amor o el tiempo mismo ${ }^{39}$. En la poesía española actual se sigue manteniendo esta tradición de escritura elegíaca, hasta el punto de que este género o «concepto genérico» ha sido considerado como «el de mayor pervivencia desde la poesía clásica greco-latina hasta la poesía contemporánea», especialmente en lo que se refiere al paso irreversible del tiempo, tema o vertiente que se ha reconocido como «todavía más continuada y fecunda» en la producción actual ${ }^{40}$.

Sin embargo, a pesar de que en los poemas de vanitas a los que se hace referencia aquí pueden detectarse reminiscencias de los poemas elegíacos tradicionales, que se aprecian sobre todo en la presencia de algunos tópicos y en ciertas estructuras compositivas, los textos contemporáneos se distinguen de estos poemas elegíacos en la distancia que guarda el hablante en relación al tema que trata. Esta distancia se manifiesta especialmente en el tono de estas composiciones, que no es, por lo general, el del llanto o el grito del que participa y sufre la pérdida -élegos: llanto-, sino más bien el de quien la contempla de forma objetiva, como se verá en el último apartado de este trabajo ${ }^{41}$.

Después de realizadas las anteriores matizaciones, me voy a centrar en el análisis de algunos poemas españoles contemporáneos que, en mi opinión, pueden ser considerados como creaciones de vanitas poética, enfocándome en las que considero como tres características fundamentales: 1) el contraste temporal entre el presente y el pasado; 2) la presencia de lo sensorial y lo material; y 3) la narrativización de lo visual mediante el discurso poético.

\section{El contraste temporal entre el presente y el pasado}

Al igual que ocurre con la vanitas pictórica, el tema central de los poemas que podrían englobarse dentro de esta categoría es el paso de tiempo y los efectos que

\footnotetext{
39 Camacho, E., La elegía funeral en la poesía española, Madrid, Gredos, 1969, pp. 9-11.

40 Ramos, M. J., "La tradición de la Elegía clásica en la poesía española contemporánea", en Maestre, J. M., (ed.), Humanismo y pervivencia del mundo clásico. Homenaje al profesor Antonio Prieto, vol. 4.1, Madrid, Alcañiz, 2008, pp. 447 y 452.

41 Ésta es precisamente una de las particularidades que José Jesús Bustos Tovar señala para las composiciones elegiacas tradicionales, la necesidad de que exista en el poema un "yo» elegíaco, es decir, que además de los elementos temáticos fúnebres se presente un discurso en el que el hablante se identifique, en algún grado, con el dolor o la pérdida que relata o enuncia el texto. Bustos, J. J., «La elegía como forma del discurso poético», en Alsina, J. (ed.), Teoría del discurso poético: actes du Ve colloque du S.E.L., Toulouse, Université de Toulouse-Le Mirail, 1986, p. 17.
} 
éste provoca sobre la materia. Para subrayar esta idea de temporalidad y de cambio, muchos de estos poemas se estructuran, siguiendo aquí una fórmula habitual de la poesía elegíaca, en torno a la oposición de dos tiempos diferenciados, el antes y el después, o el antes y el ahora, momentos a los que el texto hace referencia explícita a través de distintos indicadores temporales ${ }^{42}$.

Uno de los poemas que podría incluirse dentro de esta tipología de composiciones y que ejemplifica claramente esta primera característica es el poema «La manzana», de Juan Ramón Barat, perteneciente al poemario Piedra primaria (2004). Como muchos de ellos, este poema recrea o describe dos momentos diferentes, en este caso dos veranos, entre los que media un año de diferencia. Aunque en este caso el espacio es siempre el mismo, una habitación que da al mar, el paso del tiempo, verdadero protagonista de la composición, provoca un cambio sobre la materia de esta estancia, concretamente sobre una manzana olvidada sobre la mesa, que sufre los efectos de la descomposición:

La manzana quedó sobre la mesa.

Era roja y hermosa como un sueño.

Exhalaba un aroma fresquísimo de bosque

que embalsamaba el aire

de aquella habitación que daba al mar.

En su forma perfecta

podía resumirse el mundo todo.

Un silencio de seda acariciada

se posaba en su piel y temblaba la vida

en la pulpa jugosa de su carne.

Pasó el tiempo. Volvimos

el verano siguiente. Los gusanos

habían devorado la manzana.

Sobre la pobre mesa sólo había

una sombra de polvo,

un olor de humedad y de maderas viejas.

Tampoco había rastro de gusanos. .43

Mediante la evolución temporal, en este poema se oponen dos manzanas, o mejor dicho, dos estados diferentes de la misma manzana, la manzana del pasado, que se encuentra en la plenitud de su forma, y la manzana del futuro de ese pasado,

42 Como señala Eduardo Camacho: «La estructura elegíaca sigue siendo, fundamentalmente, contrastada, el ritmo "pendular" (...). A veces, en los siglos XVI y XVII, tal estructura contrastada se acentúa por medio de ciertos recursos tales como el que llamaremos ruptura, mientras el movimiento de vaivén se hace más claro y tajante mediante la fórmula "Ayer... Hoy..."». Camacho 1969, op. cit. (nota 39), p. 177. El subrayado es del original.

43 Barat 2004, op. cit. (nota 6), p. 18. 
que ha sido devorada por los gusanos. Lo que media entre un estado y otro es el paso del tiempo, formulado en el poema explícitamente - «Pasó el tiempo»-, frase que divide el texto en dos partes y marca la diferencia entre el antes y el después.

Un poema parecido al anterior, aunque menos explícito y con un recorrido temporal inverso, es el poema «Un vaso con anémonas», del poemario Elegías (1984), de Eloy Sánchez Rosillo.

En él, el hablante reflexiona en el momento presente de la enunciación sobre el paso del tiempo y sobre la pérdida que éste provoca, que es, en este caso, una pérdida amorosa. Esta reflexión le conduce, en una reformulación del tópico del $u b i$ sunt? propio de la poesía elegíaca ${ }^{44}$, a interrogarse por el destino o la fortuna de la persona amada y de los días que ambos compartieron. Ese tiempo pasado, que se asocia poética y simbólicamente con la primavera, se identifica también con el espacio de una habitación, en una transposición de lo temporal a lo espacial que resulta muy frecuente en este tipo de composiciones. Como señala Gómez Toré, lo elegíaco, construido siempre a partir de la pérdida, remite a un momento y a un lugar en el que se tuvo, o se creyó tener, lo añorado, por lo que opone el tiempo y el espacio de la ausencia, al tiempo y al espacio de la posesión:

Lo elegíaco proyecta por tanto una dialéctica entre un aqui y ahora marcados por el dolor frente a un alli y entonces dichosos. Esta contraposición entre el contexto de la ausencia y el de la presencia lleva a vincular profundamente el tiempo y el espacio. El tiempo de felicidad se confunde con el lugar dichoso y viceversa. 45

Este lugar dichoso aparece representado o simbolizado sinecdóquicamente en el poema de Eloy Sánchez Rosillo mediante la presencia de ese «vaso con anémonas», que recuerda aquí a los cuadros de bodegones conocidos como «floreros»46. La mención de ese vaso, tanto en el título como en el texto, tiene claras resonancias pictóricas e introduce en el poema una imagen visual y sensorial que el hablante ofrece a los lectores mediante la descripción de los detalles de la escena y de su iluminación, que se presenta, así, en su composición y estatismo, como si de un cuadro se tratara:

\footnotetext{
44 Camacho 1969, op. cit. (nota 39), p. 17.

45 Gómez, J. L., La mirada elegíaca, Valencia, Pre-Textos, 2002, p. 43. El subrayado es del original.

46 Lily Litvak recuerda la difusión que tuvieron durante el siglo XIX los libros dedicados a la «floriografía», como, por ejemplo, El vaso de flores, de Miss S. C. Edgarton, o El lenguaje de las flores, de Mme Charlotte de la Tour. Estos libros ofrecían un listado de distintas flores y plantas, acompañado de los sentimientos que se otorgan a cada una de ellas y contribuyeron a consolidar y difundir un lenguaje floral de circulación común, que era conocido por distintos poetas y artistas. Litvak 1998, op. cit. (nota 30), p. 39.
} 
Ya no me queda nada de los años aquellos. El olvido, lentamente, lo ha ido borrando todo, y es tu imagen la sola luz que a veces aún brilla en tanta noche. Qué habrá sido de ti, de aquellos ojos que siempre me miraban cual si las horas fueran eternas por ser bellas, tiempo quieto y sin muerte.

Dónde estarás, dónde estarán los días de nuestra desvalida primavera el cuarto aquel, el sol que en el crepúsculo acariciaba un vaso con anémonas. 47

El contraste entre el presente y el pasado se representa aquí a través de la oposición luz/oscuridad, que se convierte en una oposición imagen/carencia de imagen. Mientras el pasado es un tiempo que se caracteriza por la presencia de la luz y de las imágenes -tiempo de «primavera», de la luz de la amada y la luz del sol sobre las anémonas-, el presente es un tiempo de oscuridad, de «noche» y de «muerte», en el que estas imágenes están ausentes, puesto que el olvido, consecuencia del paso del tiempo, se ha encargado de borrarlas, dejando al hablante con su ausencia o su vacío, es decir, con «nada». Esta nada se anuncia ya en el primer verso del poema, cuyo recorrido es, como ya se indicó, retrospectivo, y va desde el tiempo negativo del presente al «tiempo quieto y sin muerte» del pasado, que, igual que en la mayoría de estos poemas, se valora como algo positivo.

El mismo motivo artístico del vaso con flores como excusa narrativa u origen de la reflexión sobre el paso del tiempo aparece en el poema de Vicente Gallego «Variación sobre una metáfora barroca», de Los ojos del extraño (1990). Como indica el título, el poema reutiliza la recurrente metáfora barroca de la rosa para recrear el tema de la plenitud o la vida que se corrompe con el tiempo, tema asociado tradicionalmente a los tópicos literarios de la brevitas y el carpe diem, y convertido durante el periodo barroco en uno de los emblemas o símbolos de la inconstancia que mejor representa el paso del tiempo y la fugacidad de la vida 48 .

En el mencionado poema, se otorga a la rosa el mismo significado de emblema de la inconstancia que ésta tiene en la tradición, e igual que en muchos otros textos, su descomposición da pie a una reflexión sobre el tiempo y sobre la actitud que debe adoptarse ante su transcurso:

Alguien trajo una rosa

hace ya algunos días, y con ella

trajo también algo de luz,

47 Sánchez 1984, op. cit. (nota 7), p. 24

48 Andrés 1994, op. cit. (nota 23), vol. 1, p. 45. 
yo la puse en un vaso y poco a poco

se ha apagado la luz y se apagó la rosa.

Y ahora miro esa flor

igual que la miraron los poetas barrocos,

cifrando una metáfora en su destino breve:

tomé la vida por un vaso

que había que beber

y había que llenar al mismo tiempo,

guardando provisión para días oscuros;

y si ese vaso fue la vida,

fue la rosa mi empeño para el vaso.

Y he buscado en la sombra de esta tarde

esa luz de aquel día, y en el polvo

que es ahora la flor, su antiguo aroma,

y en la sombra y el polvo ya no estaba

la sombra de la mano que la trajo. 49

Nuevamente se aprecia aquí la oposición temporal que constituye la base de estas composiciones. La rosa de «hace algunos días» es la rosa rebosante de vida que, igual que la manzana y las anémonas de los poemas anteriores, se convertirá en polvo, al «apagarse» y convertirse en la rosa «de esta tarde».

Este contraste o separación de tiempos se traduce también, en términos literarios, en una división textual. La línea de corte o de transición temporal del poema, ese momento capital en el que el antes se separa o se diferencia del después, funciona, así, a modo de eje o bisagra que divide el texto en dos partes, y que recuerda la forma de aparición de algunas pinturas de vanitas, pintadas u ocultas «al reverso» de otra pintura, y que funcionan muchas veces como su complemento o su continuación ${ }^{50}$. Al igual que en estos casos de vanitas al reverso, la división del texto en dos partes o «tablas» tiene una doble función. Por un lado, una función narrativa que da cuenta gráficamente, tanto en la pintura como en la poesía, de la secuencia o la sucesión de los acontecimientos, al mostrar lo que pasará después; el estado en el que se encontrarán las cosas y los seres en un momento posterior al presentado frontal o inicialmente, en el reverso del tiempo. Pero además de esta función

49 Gallego 1999, op. cit. (nota 8), pp. 792-793.

50 Montserrat Prieto señala precisamente como antecedentes del género de la naturaleza muerta algunas composiciones que fueron pintadas al reverso de otros cuadros. El primero de ellos es una «Madonna», pintada por un alumno de Roger Van Der Weyden en 1470, en cuyo dorso aparece una naturaleza muerta compuesta por varios elementos que se asocian al tema de la Anunciación. Otro antecedente sería el cuadro «Jarrón de flores en una hornacina», pintado en 1490 por el alemán Hans Hemling, que aparece al dorso de una tela en la que el autor había pintado el retrato de un hombre. Prieto 1987, op. cit. (nota 26), p. 29. 
narrativa, y paralela a ella, la contraposición de dos tiempos y de dos estados de la materia tiene una segunda función, que es la de velar y revelar al mismo tiempo la verdadera naturaleza de las cosas, en un juego paradójico de presentación y ocultamiento, de afirmación y negación. Así, con esta duplicación no sólo se hace hincapié en el estado futuro de la materia, sino que su esencia misma se muestra, en tiempo presente, como materia vana, perecedera y susceptible de corrupción, con lo que también se llama la atención sobre su «engañosa» apariencia. Lo frontal o lo real, lo que se ofrece como verdadero, no es más que una máscara o un disfraz de la vejez, la corrupción y la muerte, que no se encontrarían ya, según esta idea, al final del tiempo o al otro lado de todas las cosas, sino que están siempre presentes, como germen, en la propia naturaleza de los seres vivos, contra la que no existe escape ni huida posible.

La constatación de que la materia es vana y susceptible de corrupción hace surgir inmediatamente la reflexión sobre la muerte, ante la que caben, al menos, dos posibilidades: o bien se rechaza lo material, en función de un más allá religioso o trascendente, o se intenta aprovechar y gozar esa materia condenada irremediablemente a desaparecer, opciones por las que el arte se ha inclinado en una u otra dirección a lo largo del tiempo.

\section{La presencia de lo materia y lo sensorial}

Además del tema central del paso del tiempo y sus efectos, las composiciones de vanitas prestan especial atención al aspecto sensible de la materia y en cómo ésta incide y afecta a los sentidos. Como afirma Joëlle Busca: «La peinture de vanité s'adresse directement au corps du spectateur, à sa sensualité, à sa frayeur, à ses capacités synesthésiques» 51 .

Desde el inicio, muchas de las composiciones de bodegones y naturalezas muertas estaban dirigidas a decorar las estancias de las viviendas destinadas a la comida ${ }^{52}$ y tenían la función de estimular el apetito de los comensales ${ }^{53}$.

Durante la época barroca, esta idea se combina con el miedo al paso del tiempo y a la muerte propios de este periodo, lo que conduce a la necesidad de gozar de la vida todo lo que se pueda, para evitar un posterior sentimiento de no haber vivido lo suficiente. Por ello, como señala Ramón Andrés, es una constante del arte de esta época, extremadamente sensorial y rico en volúmenes, color y contraste de luz, la búsqueda de diferentes formas de deleitar y de exaltar los sentidos, motivo que

\footnotetext{
51 Busca, J., Miquel Barceló. Le triomphe de la nature morte, Bruxelles, La Lettre volée, 2000, p. 14. 52 Triadó, J. R., "Bodegones y pintura de bodegón”, en Sobregués, N., (ed.), El bodegón, Barcelona, Fundación amigos del museo del Prado-Galaxia Gutenberg, 2000, p. 47.

53 Orozco 1989, op. cit. (nota 38), p. 20.
} 
explica la abundancia de frutas y flores en las obras de este periodo, así como de piezas de cacería y reconfortantes vinos, como parte de toda esa materia delectable que ofrece la naturaleza 54 .

En pintura, la forma de aludir a los sentidos tiene que ver con la inclusión o la representación de objetos que recuerden o evoquen la experiencia sensible. Como señala Montserrat Prieto, en los cuadros de vanitas:

los sentidos corporales, tantas veces aludidos en la literatura piadosa, son evocados de inmediato ante un espejo (la vista), unas frutas o cualquier otro comestible (gusto), un instrumento o un ave cantora (oído) y cualquier tela rica, animal de piel preciada o bolsa de monedas (tacto). 55

En el caso de los textos literarios, esta alusión a lo sensorial se consigue mediante la mención o la sugerencia de cualidades visuales, táctiles u olfativas, a través de la enumeración de los objetos y de su descripción y adjetivación.

En el poema «La manzana», de Juan Ramón Barat, comentado arriba, se describen de manera muy gráfica las cualidades de una manzana en la perfección de su madurez. En esta descripción existen sugerencias tanto visuales como olfativas, táctiles y gustativas. Las referencias a lo visual se encuentran en la alusión a su «forma perfecta», a su hermosura, y, especialmente, en la mención del color «rojo», símbolo y exponente no sólo del atractivo visual de esta fruta, sino también de sus cualidades simbólicas y seductoras ${ }^{56}$. Además de lo visual, la descripción de esta apetitosa manzana incluye también alusiones olfativas, en la indicación de su «aroma fresquísimo de bosque», que es tan intenso que llega incluso a «embalsamar» el aire de toda la habitación; táctiles, en la sinestesia con la que se describe su piel, de un «silencio de seda acariciada»"; e incluso gustativas, en la mención de esa "pulpa jugosa» que constituye su carne.

En los otros dos poemas mencionados se hace referencia también, aunque de manera más breve, a estas cualidades positivas de lo material. El poema de Eloy Sánchez Rosillo compara el tiempo del amor con la primavera, con lo que indirectamente se añaden al texto connotaciones visuales, táctiles y olfativas. Pero el aspecto más gráfico se consigue mediante la referencia al sol y a la iluminación que éste ofrece del objeto, que en su calidez crepuscular, y en una descripción táctil que incluye una personificación, «acariciaba un vaso con anémonas».

De la misma forma, en el poema de Vicente Gallego la rosa se presenta en su plenitud en la referencia olfativa a su «aroma», que se acompaña de una alusión

\footnotetext{
54 Andrés 1994, op. cit. (nota 23), vol. 1, pp. 45-46. El subrayado es del original.

55 Prieto 1987, op. cit. (nota 26), p. 15.

56 En estas composiciones, como señala Montserrat Prieto: «La manzana trae el recuerdo del Paraíso terrenal, el primer pecado y, por supuesto, su correlato: la Redención». Prieto 1987, op. cit. (nota 26), p. 15.
} 
visual, al mencionar la «luz» que, de manera tanto literal como metafórica, aporta su presencia.

Todas estas alusiones sensoriales contribuyen, por un lado, a subrayar el aspecto visual y plástico de estas composiciones, que se ofrecen a los ojos del lector como si se tratara de auténticas imágenes que se tuvieran ante los ojos. El hablante poético, que funciona como observador o contemplador de una realidad sensible, la transmite por medio del lenguaje y de la descripción al lector, tal como se verá en siguiente apartado. Con esto, las descripciones detalladas de estos poemas cumplen realmente la función de «pintar con palabras» que en las retóricas clásicas se atribuía a la figura de la hipotiposis.

Pero, además de esta función pictórica, la descripción sensual y detallada de los objetos y de la materia sirve para acentuar el contraste entre este estado de plenitud $\mathrm{y}$ esplendor y un estado futuro de descomposición, corrupción y degeneración. Cada una de las partes del texto presenta, así, igual que las dos imágenes o tablas de las pinturas de vanitas, la frontal y la colocada al reverso, un estado extremo de la materia -la total plenitud y la total corrupción-, con lo que el contraste o choque entre ellas se hace mucho más intenso, evidente e impactante.

En el poema de Juan Ramón Barat, la distancia temporal entre un verano y otro, cifrada o resumida en esa afirmación que divide el texto en dos partes -«Pasó el tiempo»- es la responsable del cambio en la materia, que se presenta ahora reducida a una «sombra de polvo»:

Pasó el tiempo. Volvimos

el verano siguiente. Los gusanos

habían devorado la manzana.

Sobre la pobre mesa sólo había

una sombra de polvo,

un olor de humedad y de maderas viejas.

Tampoco había rastro de gusanos. ${ }^{57}$

A partir del eje temporal mencionado, se produce un cambio radical en el poema, que puede apreciarse no sólo en el aspecto temático o del contenido, sino también en el nivel léxico y lingüístico. La adjetivación positiva de la primera parte, así como los superlativos, las metáforas y las comparaciones que se desarrollan en el ámbito de la plenitud y la perfección, se sustituyen ahora por elementos pertenecientes al campo semántico de la corrupción y la degeneración: «gusanos», «sombra», «polvo», «humedad» y «maderas viejas», produciendo como resultado un choque tanto estético como estilístico. Con este contraste se consigue llamar la atención sobre la brevedad de las cosas y la fugacidad de la vida.

57 Barat 2004, op. cit. (nota 6), p. 18. 
Esta presentación plástica y gráfica de la corrupción y la degeneración de las cosas y de los seres sirve también como una llamada a disfrutar y a gozar de esos objetos antes de que sea demasiado tarde, idea que estaba ya presente, como recuerda José Luis Gómez, en la antigua poesía elegíaca:

cuando nos acercamos a la temática funeraria en la primitiva elegía, nos topamos con la curiosa asociación entre la muerte y la celebración báquica, que nace tal vez de la entonación del canto funeral en el marco del banquete en honor del difunto. Por tanto, ya desde antiguo existía una tradición en la lírica que vinculaba el dolor de la muerte con la necesidad de aprovechar los placeres (fugaces) de la vida. La exhortación, la reflexión ética, surge así de manera natural, ya que el horizonte de la muerte nos incita a vivir con intensidad nuestra existencia. 58

Esta invitación, expresada o condensada en el tópico clásico del carpe diem, se transmite también a través de la pintura de vanitas, y se refuerza, precisamente, introduciendo algunas señales de la corrupción de la materia que permiten anticipar su final:

El tema de vanitas señala al hombre que tan trabajosamente se preocupa en atesorar bienes durante toda su vida, que ésos no lo seguirán a la tumba. (...) las flores se incluyen en estas pinturas con el significado de transitoriedad, y asimismo lo indican las frutas, tema que se refuerza cuando se incluye algún insecto posado en una de ellas, o por la presencia de manchas, machucones, o agujeros de gusano. 59

La materia y los objetos, con esa mención de los gusanos, el polvo y demás detalles de degeneración, se convierten, así, en recordatorio o memoria de la muerte, en la actualización o materialización del tópico que lleva su nombre: memento mori. Este tópico aparece recreado en un poema de Rosa Romojaro titulado, precisamente, «Recuerda», del libro Zona de varada (2001):

Esas copas que brillan como llama

y que laten al tacto de metales

ligeros -tantas copas-; esa trama

que, sobre cal, dibujan, verticales,

las hileras de libros en tapices

de olvido - tantos libros-; todos esos

atajos y caminos de matices

parejos que descubre la luz, presos

entre los montes -tantos-. Tantas cosas

iguales y cercanas, ordenadas

58 Gómez 2002, op. cit. (nota 45), p. 29.

59 Litvak 1998, op. cit. (nota 30), p. 43. 
y juntas son, más aún que las rosas,

más aún que el reloj o las azadas,

recados de la muerte: faltará

tiempo para vivirlas todas ya. 60

La palabra «recuerda» que aparece en el título, unida a la calificación de «recados» que se aplica a los objetos cotidianos en el penúltimo verso, remite claramente a la tradición de la poesía elegíaca, de la que pueden destacarse tanto el inicio de las Coplas a la muerte de su padre, de Jorge Manrique, como el «Salmo XVII» de Quevedo mencionado más arriba.

En el poema de Romojaro se enumera, de forma parecida a lo que ocurría en los poemas anteriores, una serie de objetos -copas, libros, caminos-que componen, en su disposición, el dibujo o pintura de ese bodegón o naturaleza muerta, cuya relación con la tradición del género se hace evidente en la alusión del poema a «las rosas», «el reloj» o «las azadas», elementos frecuentes y reconocibles en los cuadros de vanitas 61.

Nuevamente, la presentación y la descripción de estos objetos se detiene en los aspectos sensoriales. En una indicación visual muy gráfica y colorista, las copas «brillan como llama» y dibujan, en su orden y repetición, una «trama» vertical sobre la estantería sobre la que reposan. Además, estas mismas copas, acompañadas tal vez por platos o cubiertos, «laten al tacto de metales ligeros», en una referencia táctil que incluye una personificación. De las copas y de las hileras de libros que se observan en la habitación, se pasa, en una progresión visual de lo interior a lo exterior, a la descripción de los caminos que, contemplados tal vez a través de una ventana, se encuentran o se observan fuera, entre los montes del paisaje. Lo interesante de esta descripción o este conjunto de objetos es, además de estos aspectos sensoriales, la idea de abundancia, sobre la que se insiste repetidamente a lo largo del poema. Los objetos descritos no aparecen aislados, sino que forman parte de series o conjuntos que se presentan cuantificados: «tantas copas», «tantos libros», «todos

60 Romojaro, R., Zona de varada, Sevilla, Algaida, 2001, p. 28.

61 Además de lo ya comentado sobre la rosa como símbolo o emblema de la inconstancia por excelencia y de la obvia relación que guardan con este tema las calaveras, los esqueletos y las azadas, los libros y el reloj son también elementos característicos de las obras de vanitas en la época barroca. Por un lado, la abundancia de libros se veía en este periodo como un símbolo de ostentación, especialmente cuando se utilizaban como elementos decorativos para el «atavío de las cámaras», en lugar de su función propia de «atavío de los ánimos». Por otro, el reloj funcionaba como recordatorio perfecto del tiempo y su transcurso. Como recuerda Ramón Andrés: «El espíritu barroco se pregunta en qué momento acabará todo, razón que le lleva a medir obcecadamente ese proceso de desenlace que es la vida. La medición del tiempo supone tasar el final. No en vano, el auge del arte de la relojería tuvo lugar entonces (...). El reloj fue un distintivo de aquellas generaciones, una marca que no podía faltar en la vanitas -mecánico, de mesa, de sol, de agua, de campanilla; se trataba de un instrumento que avivaba como ninguno la conciencia del presente». Andrés 1994, op. cit. (nota 23), vol. 1, pp. 46-48 y 81. 
esos/ atajos y caminos», «tantas cosas/ iguales y cercanas». La mención de toda esta abundancia tiene aquí la misma función de intensificar el efecto negativo y devastador del tiempo, que, en su limitación, impedirá disfrutar y gozar de ella: «faltará/ tiempo para vivirlas todas ya». Este lamento final de la hablante resume la preocupación que subyace bajo todas estas composiciones: la imposibilidad de permanecer y la consiguiente necesidad de renunciar a los objetos y a la materia. Aunque en este caso no se ofrecen detalles concretos de la degeneración material, ésta queda aludida en la mención del poco tiempo del que dispone la protagonista del poema, con lo que se hace referencia, de manera indirecta, a un final tal vez próximo y a su consiguiente desaparición.

Como se ha visto en este apartado, las representaciones de vanitas no se limitan a la simple presentación de los objetos o los seres vivos, sino que muestran también su evolución, su cambio, su transformación. Esta transformación resulta fundamental para la caracterización de los poemas de vanitas, y, en mi opinión, es un rasgo que puede tomarse como un criterio válido para distinguir estas composiciones de los bodegones, que tendrían un carácter más general o menos específico. Mientras que los textos que pueden considerarse como recreaciones de vanitas presentan dos estados de la materia en una construcción dinámica, los bodegones suelen limitarse a ofrecer un momento o estado puntual y estático de los mismos, sin mostrar ni sugerir ningún tipo de evolución.

Esta diferencia puede apreciarse en el poema «Bodegón», de Carmen Pallarés, en el que, gracias al artificio del espejo y del reflejo que éste proporciona, los objetos pasan a formar parte de una realidad duplicada, contenida dentro de los límites de este espejo que hace aquí las veces de marco o de cuadro:

\author{
En el espejo \\ los bordados, las sillas, \\ la inútil chimenea, las naranjas \\ amarilleando, la camomila, \\ el libro. En la hipérbole del espejo \\ el extraviado, ella, los dos \\ marinos, la anciana, Pinemía, el gran gato. \\ Todo: la miel, el pan y la pimienta, \\ las baldosas etílicas, los cuchillos, la tarde \\ que se viene; el espejo así inmortalizado \\ por la vida y sus innumerables \\ puntos de fuga, espontáneamente \\ dispuesto por la mano \\ meticulosa de la belleza. 62
}

62 Pallarés, C., «Bodegón», en Reina, M. F., (ed.), Mujeres de carne y verso. Antología poética femenina en lengua española del siglo XX, Madrid, La esfera literaria, 2002, p. 302. 
A diferencia de los anteriores, este poema se limita a ser una descripción de los objetos cotidianos que, igual que en un bodegón pictórico, se ofrecen de manera estática, sin que exista ninguna alusión al paso del tiempo ni a la transformación de la materia, ni ninguna referencia alegórica o simbólica derivada de estas ideas. Además, la hablante del poema ve limitada su participación a la descripción más o menos objetiva de los objetos, sin implicarse emocional o subjetivamente. En los poemas de vanitas, por el contrario, y según lo propuesto en este trabajo, deben funcionar los tres rasgos arriba mencionados: el paso del tiempo y sus efectos sobre la materia, las alusiones a lo sensorial, y la percepción o la reflexión del hablante poético, que traduce o traslada lo que ve al discurso del poema. Estas características, que están presentes en los textos analizados aquí, se encuentran también, por ejemplo, en el poema «Bodegón», de Rafael Espejo, que puede utilizarse como contraste con el poema anterior, y que ofrece una solución original a la necesaria idea de la transformación de la materia indicada:

Sobre una mesa de madera pobre y en cuenco de terrazo, unos trozos de pan y tres naranjas acompañan al vaso ensombrecido de vino rojo.

La pintura del lienzo está rugosa

como la idea:

naturaleza muerta, las estrías del tiempo, la luz fosilizada.

No hay nada en él de humanidad. La mano que indagaba en las esencias sólo plasmó lo estéril.

(Ni polvo quedará de aquellos dedos...)

Pero debajo, tras una de las grietas del color, nace el milagro de la primavera: una colonia de hongos

la regeneración de la materia reivindica, orgullosa, en el arte insensible,

mortal como la carne y acaso tan hermoso. 63

63 Espejo 2003, op. cit. (nota 5), p. 136. 
El paso del tiempo se constata en este poema, una vez más, en la mención del "polvo" en el que se han convertido los dedos del pintor que pintó el cuadro, así como en la calificación de la carne como «mortal». Sin embargo, al ser aquí lo contemplado un cuadro y no la realidad o la materia viva, el aspecto más gráfico de esa corrupción lo proporciona el envejecimiento, no de las cosas, sino de la tela, en la que ha brotado «una colonia de hongos», que, sin embargo, y paradójicamente, es la que otorga vida a las de por sí inmóviles y estáticas representaciones artísticas. Con esta idea se plantea una reflexión sobre el arte y su relación con la realidad, que puede cifrarse en términos de fijación inmóvil, como en el poema anterior -«luz fosilizada», «lo estéril», «el arte insensible»-, o bien verse como salvación o perpetuación de esa realidad, como se verá en el apartado siguiente. En esta última idea se conjugan, por un lado, los tópicos de la consolación de la poesía elegíaca, entre los que se encuentra el de la perpetuación o supervivencia por el arte o la fama ${ }^{64}$, y por otro, la contradicción intrínseca que subyace en toda vanitas pictórica, que propone una reflexión sobre lo fugaz y lo pasajero a través de la fijación de una forma artística estática y permanente 65 .

\section{La narrativización de lo visual a través del discurso poético}

Además de las dos características señaladas en los apartados anteriores, en los poemas de vanitas se produce un interesante juego entre lo pictórico y lo poético, que tiene que ver con la narración o la narrativización de lo visual y su conversión en texto. Por un lado, los poemas presentan un escenario de objetos y elementos, distribuidos o colocados, la mayoría de las veces, en espacios interiores. Esta distribución de los objetos se asemeja, en sí misma, a la de los cuadros de bodegones o naturalezas muertas de la tradición artística. Pero, al tratarse en este caso de poemas, y no de auténticos cuadros, los textos necesitan una presencia humana responsable de percibir, o simular percibir, primero, los objetos referidos, y de transmitir o relatar, después, lo percibido a través de su discurso. Se produce así lo que podría

64 Como señala Bruce Wardropper, las finalidades de la elegía pueden ser dos: retórica, según la cual el poeta busca explicar la muerte y persuadir o convencer de su necesidad y su inevitabilidad; o bien poética, por medio de la cual, el poeta busca no tanto explicar la muerte como trascenderla en la continuidad de las obras artísticas que haya creado o en los hijos que haya engendrado. Wardropper, B., Poesía elegíaca española, Madrid, Anaya, 1967, p. 11. Esta idea de la transcendencia por las obras o la fama se cuestiona de forma irónica en el poema "La eternidad ansiada", de Carlos Marzal. Marzal, C., Los países nocturnos, Barcelona, Tusquets, 1996, pp. 101-102.

65 Joëlle Busca reflexiona sobre esta idea de la siguiente manera: "Rien n'est plus trompeur que ces épithètes de mort (nature morte) ou de tranquille (still life), le genre est au contraire bavard et remuant: il y demeure un souffle de vie qui se débat pour être encore et que sauve la peinture. Le peintre, dans le même geste, pratique la médecine opératoire, la dissection et la réanimation”. J. Busca 2000, op. cit. (nota 51), p. 15. 
llamarse, en términos generales, y retomando la expresión de Michael Riffaterre, una «ilusión de écfrasis»66, puesto que el hablante del poema parece estar contemplando una realidad que describe, pero que no debe entenderse de manera referencial sino ficcional, puesto que sólo existe dentro del poema.

En esta operación, es la mirada del observador, del hablante poético, la que focaliza y delimita los objetos de su contemplación, construyendo una especie de lienzo o cuadro imaginario, que después será trasmitido o descrito de forma verbal, en una operación de selección visual que se asemeja mucho a la realizada por el pintor, y que es precisamente la que otorga originalidad a este género pictórico. Como señala Emilio Orozco, en el momento de aparición de los bodegones o naturalezas muertas, la novedad de estas representaciones consistía en la conversión de lo que hasta entonces había sido puramente anecdótico en tema central de la composición, y en la separación realizada por el artista, el pintor en este caso, del trozo o el fragmento representado del conjunto de la realidad67.

Para subrayar esta separación entre el observador y lo observado, entre el sujeto y el objeto, se hace explícita muchas veces la presencia del límite, que, en forma de marco, cuadro o espejo, como en el poema de Carmen Pallarés, sirve para separar o delimitar los distintos niveles de realidad o existencia de las cosas, en un artificio que aparece en la poesía contemporánea, pero que tiene sus antecedentes en algunas composiciones pictóricas tradicionales del género68.

Con la retransmisión o la narración de lo visto por parte del hablante, estos poemas introducen una cierta distancia entre lo observado y el observador, que hace que estos textos no sean sólo poemas subjetivos o líricos, en sentido estricto, sino también poemas narrativos o narrativizados. Esto se observa en la forma gramatical

66 Riffaterre, M., «La ilusión de écfrasis», en Monegal, A., (ed.), Literatura y pintura, Madrid, Arco/Libros, 2000, pp. 161-183.

67 Orozco 1989, op. cit. (nota 38), p. 18.

${ }^{68} \mathrm{La}$ idea de marco o ventana resulta fundamental para muchos cuadros de bodegones y naturalezas muertas que se representan dentro de determinados recuadros o huecos, en una imitación del espacio real en el que solían colocarse los objetos representados. Algunos pintores de bodegones, como por ejemplo el español Juan Sánchez Cotán, utilizan de forma recurrente este artificio de enmarcar o delimitar los elementos de sus composiciones mediante un recuadro o una ventana, que no tiene más función que la de ser una construcción imaginaria, un recurso pictórico sin ninguna intención realista o figurativa: «En todos sus bodegones conocidos Sánchez Cotán se contentó con componer dentro del mismo formato de esa ventana que parece ser su contribución personal y muy influyente a este género de pintura (...). Aunque es posible que la inspiración de emplear esa clase de hueco viniera del cantarero o fresquera de las casas de la época, el hecho de que en el inventario se utilice la palabra "ventana" concuerda con su función como recurso pictórico. Al ser el hueco de la ventana una construcción imaginaria, ni se representa en términos naturalistas, ni se muestra una pared al fondo, ni puertas, ni hay junturas ni señales de desgaste en el yeso o la piedra de que podría estar hecha». Peter Cherry, «El ojo hambriento: los bodegones de Juan Sánchez Cotán», en Sobregués 2000, op. cit. (nota 52), pp. 249-250. 
elegida para estos textos, en los que el hablante no suele expresarse en primera persona, sino, por lo general, en tercera o segunda, dejando ver, así, una distancia con lo referido propia de un narrador69. Esta distancia del hablante en relación con el enunciado se aprecia de manera especial en los casos en los que el poema se construye con el artificio del monólogo dramático, en los que la primera persona no se corresponde o no puede identificarse con el yo-autor, sino con un personaje histórico o ficcional. Esto ocurre, por ejemplo, en el poema «Conocimiento del reino submarino», de Javier Rodríguez Marcos70, en el que el que habla en el poema es el esqueleto de un hombre muerto en un naufragio.

La función del hablante en estos poemas es, según esto, doble, con lo que se resalta el carácter híbrido de estas composiciones. Por un lado, y derivada de las reminiscencias pictóricas, tiene una función narrativa de contar o relatar lo que ve; pero, por otro, se encuentra inmerso en la situación comunicativa que relata, con lo que se introducen en el texto aspectos subjetivos y líricos, así como alusiones al acto mismo de la enunciación mediante la deixis espacio-temporal, en lo que parece ser una característica propia y necesaria del discurso elegíaco ${ }^{71}$.

Esta deixis o demonstratio ad oculos, según la terminología de Karl Bühler72, sirve precisamente para aludir a algo que se encuentra fuera del texto, en el campo perceptivo de los interlocutores, y en estos poemas contribuye a la construcción de la ficción de écfrasis mencionada, según la cual el hablante describe y comenta un cuadro o una escena que tiene a la vista en el momento de la enunciación del poema.

Mediante esta deixis, el hablante traslada a los lectores la situación en la que se encuentra, con lo que sus ojos funcionan a modo de ese marco o ventana señalada más arriba para las composiciones pictóricas, pero añadiendo, al mismo tiempo, la posibilidad de la introspección propia del discurso lírico. Como señala Lily Litvak, comentando el poema «Naturaleza muerta» de Rubén Darío: «La ventana allí es símbolo de los ojos del poeta, que al contrario de la visión externalizada del pintor, puede llegar hasta la esencia de las cosas, $\mathrm{y}$, a través de la escritura, eternizarlas» ${ }^{73}$.

Este tipo de alusiones a la situación comunicativa del hablante estaba ya presente en algunos de los poemas comentados hasta aquí. Por ejemplo en el poema «Vaso

\footnotetext{
69 Bustos 1986, op. cit. (nota 41), pp. 12-14.

70 Rodríguez, J., Naufragios, Mérida, Editora Regional de Extremadura, 1995, p. 50.

71 José Jesús Bustos Tovar declara en este sentido lo siguiente: «Lo que en mi opinión define el discurso elegíaco es su modalización, esto es, el modo en que se hacen presentes en el enunciado el emisor, en su doble perspectiva de yo-autor y yo-poético, y el receptor, que puede sufrir idéntico desdoblamiento. A ello deben añadirse los elementos del componente pragmático, que se manifiestan principalmente por medio de la situación, la deixis y la expresión del tiempo-aspecto del proceso». Bustos 1986, op. cit. (nota 41), p. 14.

72 Bühler, K., «El campo mostrativo del lenguaje y los demostrativos», Teoría del lenguaje, Madrid, Revista de Occidente, 1961, (2a. ed. esp.), pp. 107-187.

73 Litvak 1998, op. cit. (nota 30), p. 49.
} 
con anémonas», de Eloy Sánchez Rosillo, el contraste entre el presente y el pasado se subraya mediante la oposición entre el «ya» del ahora y los demostrativos que indican la lejanía o la distancia de lo perdido: «los años aquellos», «aquellos ojos», «el cuarto aquel». De la misma forma, en el poema de Rosa Romojaro, los objetos que se enumeran aparecen precedidos de los demostrativos que marcan o indican la mayor o menor cercanía que con ellos mantiene la hablante: «Esas copas», «esa trama», «esos atajos y caminos». Además de éstos, un poema en el que puede apreciarse claramente esta inclusión de detalles relativos al entorno en el que se encuentra el hablante es el poema «Bodegón», de Guadalupe Grande. Este texto se inicia con la descripción detallada de las circunstancias espacio-temporales que acompañan o preceden a la observación de los objetos:

Las nueve y la cocina está en penumbra:

estoy sentada ante una mesa tan grande como el desierto, ante unos alimentos que no sé cómo mirar, y si les preguntara, ¿qué me contestarían?

$$
\text { ... }
$$

La tarde se dilata en la cocina

y aquí no llega el sonido del mar.

La soledad de las naranjas se multiplica:

no hay pregunta para tanta opulencia, aquí, en la serenidad de esta banqueta de tres patas, rodeada de una muralla de mandarinas huérfanas. ${ }^{74}$

La misma idea queda todavía más clara en el extenso poema "Giorgio Morandi», perteneciente al poemario Las lecciones del tiempo (1998), de Juan Lamillar. En la sección primera de este poema, y gracias al artificio del monólogo dramático, es el propio Giorgio Morandi, pintor de bodegones y naturalezas muertas, quien presenta a los observadores/lectores los objetos y los cuadros que se encuentran en su estudio, que se ofrecen o se describen para la contemplación general. Con esta invitación, el poema se abre a la mirada del lector, a quien se incluye en el texto, con lo que se borran los límites entre el arte y la realidad, entre el «cuadro» y el espectador, en un artificio típico del Barroco:

Estos son los objetos. Miradlos. Son sencillos:

un embudo, una taza, las cajas, las botellas.

También están la luz, la quietud de las sombras.

$\mathrm{Y}$ con ellos dibujo una frontera

entre el tiempo y la nada, entre lo inmóvil

y la vida que surge de lo inmóvil.

74 Grande 1998, op. cit. (nota 2), pp. 606-607. 
Con un gesto de mago los coloco de nuevo, cambio su espacio, cambian sus sólidas aristas, el brillo de sus lentas superficies, y el mismo cuadro es otro, y me interroga. 75

Además de hacer alusión a los elementos que se tienen ante la vista mediante la deixis del demostrativo: «Estos son los objetos» 76 , el poema introduce, como ya se comentó, una reflexión sobre el arte y sobre el acto de la creación. El artista, el pintor, se equipara aquí a un mago, en su capacidad de disponer y modificar los elementos de la realidad, en una composición a la que se califica ya directamente como «cuadro». La ilusión de écfrasis, presente en todos estos poemas de manera más o menos evidente, se hace aquí explícita con esa mención, y se pone de manifiesto la existencia de los dos planos o los dos niveles que operan en estos textos: el visual, en el acto de pintar los cuadros; y el textual, en el hecho de describir esta acción mediante un discurso que es el poema que leemos los lectores.

La misma idea se repite nuevamente en la sección $\mathrm{V}$ de este poema. En ella, el hablante, de nuevo Morandi, parece estar pasando revista a sus propios cuadros, que son, precisamente «naturalezas muertas», según se deduce de la enumeración de títulos que encabeza el poema:

«Naturaleza muerta», «Naturaleza muerta

con guitarra», «Naturaleza muerta».

Soy el que ordena, el que resucita

volúmenes, objetos, escenarios,

el que libera de la muerte y traza

líneas de vida en las naturalezas

que tan tempranamente buscan

las lindes de la sombra:

alta alquimia del alba transformando

en luz creciente el reino de lo oscuro. 77

75 Lamillar, J., «Giorgio Morandi», Las lecciones del tiempo (1992-1996), Valencia, Pre-Textos, 1998, p. 41.

76 Este tipo de estructuras o fórmulas presentativas, formadas por el pronombre demostrativo seguido de una oración de relativo y acompañadas, en ocasiones, del verbo «ver» en variantes como «Este/a que veis» y similares, son, tal como señala José María Ferri Coll, expresiones frecuentes en la poesía del española del s. XVII, que, a imitación de las utilizadas en la poesía latina, sirven para ofrecer al lector el campo mostrativo que se va a desarrollar en el poema y para situarlo en el escenario recreado en el texto, al tiempo que dejan ver la cercanía o la inmediatez que guarda el poeta o el hablante con lo referido. Para este tema, consúltese: Ferri Coll, J. M., «Estos, Fabio, ¡ay dolor!, que ves ahora», Las ciudades cantadas. El tema de las ruinas en la poesía española del Siglo de Oro, Alicante, Universidad de Alicante, 1995, pp. 94-102.

77 Lamillar 1998, op. cit. (nota 75), p. 45. 
Todos estos cuadros que el hablante parece estar contemplando repiten el mismo tema de las naturaleza muerta, frase o título que aparece entre comillas y que, de esta forma, se opone, en un nivel distinto de realidad ontológica, a la otra naturaleza de la que se habla en el poema, las «naturalezas» de la realidad, «que tan tempranamente buscan/ las lindes de la sombra», es decir, que están, al igual que en los otros poemas, destinadas a su corrupción o finitud. Una vez más es el creador el que con su acción inmortalizadora rescata a estos objetos de su destino inevitable, de su muerte, y los vuelve a la vida. La idea del mago mencionada en el poema anterior se sugiere aquí mediante la alusión a la «alquimia», y la idea de dios o demiurgo aparece también nuevamente contenida en la forma que se elige para la expresión o la autoproclamación de esta identidad: «Soy el que ordena, el que resucita», frase que tiene claras resonancias bíblicas.

Además de Lamillar, otros poetas subrayan la acción positiva o inmortalizadora de la escritura y el arte. Es el caso, por ejemplo, de Víctor Botas y su poema «Una vez mas el tema (el viejo tema) de la rosa», perteneciente a su libro Historia antigua, de 1987:

Tu lejana quietud y esa apariencia que la tarde te ofrece de indecisa roja gota de sangre, de algún modo que no acierto a atender, me están pidiendo que hoy me dirija a ti, precario adorno de un jardín que no es mío. Pese a todo pese a la fiel cancela que te aparta de mí, sé que me perteneces. Nunca quien así te preserva podrá darte lo que ya te estoy dando: que la breve humedad de tus pétalos resista más que las firmes rejas que te guardan. ${ }^{78}$

El tema de la preservación o la perpetuación de la realidad por el arte, que está relacionado con los tópicos de la consolación propios de la poesía elegíaca, como ya se mencionó, se aúna en este poema a las referencias metapoéticas, pues la forma de conservar la rosa es, precisamente, inmortalizarla en un texto a través de la escritura, a cuyo proceso y devenir se hace referencia en el poema mismo: «lo que ya te estoy dando», presente continuo con el que se alude nuevamente al acto de la enunciación y a sus circunstancias.

Además de los poemas analizados hasta aquí, en la poesía española contemporánea hay otras composiciones que presentan el mismo tratamiento temático y que

78 Botas, V., «Una vez el tema (el viejo tema) de la rosa», en Martínez (ed.) 1997, op. cit. (nota 16), p. 61. 
podrían incluirse en esta categoría de vanitas poética. Entre ellos se encuentran, por ejemplo, «Cementerio», de Fernando de Villena (1985); «Objetos cotidianos»y «Los adioses», de Juan Lamillar (1992); «El tiempo sí regresa», de Concha García (1994); «Tiempo» y «Conocimiento del reino submarino», de Javier Rodríguez Marcos (1995); «Inscripción», de Eloy Sánchez Rosillo (1996); y «Hoja labrada», de Miguel Ángel Velasco (2006).

Creo que la existencia de éstos y otros poemas permite hablar de una recuperación y una reescritura del género de la naturaleza muerta, en su modalidad específica de vanitas, que no se presenta como un caso aislado o excepcional, sino que, tanto en el número de textos como en la coherencia de su tratamiento, se confirma como un interés común y recurrente en la poesía española contemporánea.

Este interés se manifiesta como una tendencia u orientación horizontal, que no se asocia con ningún grupo o generación poética particular, sino que se desarrolla en autores de distinta procedencia y estilo, que tienen en común el hecho de haber publicado sus poemas en los últimos 30 años, y el compartir las circunstancias sociales y culturales propias del cambio de siglo y de la posmodernidad.

En la reescritura de este género juega un papel fundamental la tradición, tanto pictórica como poética, que funciona como un código que los escritores demuestran conocer y con el que dialogan en los textos. En esta recuperación de la tradición pueden apreciarse reminiscencias culturales múltiples y variadas, entre las que se encuentra tanto el Antiguo Testamento, como la poesía clásica, medieval y renacentista; la poesía elegíaca, la pintura de xenion o xenia, y la pintura de bodegones y naturalezas muertas de la época barroca; así como tópicos temáticos tradicionales como vanitas vanitatum, ubi sunt?, brevitas, tempus fugit, in ictu oculi, memento mori o carpe diem.

De todas las influencias o tradiciones señaladas, resulta especialmente importante la tradición pictórica, concretamente los cuadros de bodegones y naturalezas muertas, que funcionan, en mi opinión, como motivación o punto de partida de muchas de las composiciones contemporáneas. Me parece que la escritura de estos poemas sigue muy de cerca esta tradición pictórica, ya que en ellos se hace referencia tanto a las acciones de disponer los elementos, contemplarlos y pintarlos, como al cuadro mismo, o se utilizan estos elementos y actividades como estrategias o recursos compositivos de los textos. Esta influencia puede apreciarse tanto en las abundantes alusiones que existen en los poemas a la forma, al color, a la iluminación o a la disposición de los objetos, como en el recurso de la écfrasis poética y la descripción de cuadros o imágenes que ésta realiza.

Aunque la escritura de estos poemas de vanitas no puede considerarse algo novedoso ni original, sino que forma parte de una tradición que ha estado siempre muy presente en la poesía española, resulta interesante el hecho de que muchos autores elijan este tema en la actualidad para su recreación. 
Esta preferencia revela cierta simpatía o afinidad con las inquietudes de la época barroca y de la poesía elegíaca, y al mismo tiempo muestra la lectura o la interpretación actual de las composiciones tradicionales. Aunque en los textos contemporáneos no puede hablarse ya de una interpretación religiosa como tal, la recreación que éstos realizan del tema de la vanitas, que podría catalogarse como una tendencia de orientación más culturalista que social79, no se limita nada más a su aspecto estético, sino que incluye un contenido simbólico, moral o trascendente, cuyo tono abarca desde la simple constatación del paso del tiempo, de forma generalmente comedida, a la invitación más o menos explícita a gozar de la vida y de los sentidos. De esta forma, se combinan en estos textos las dos funciones tradicionales de la poesía elegíaca, la retórica, que intenta explicar el paso del tiempo y la muerte y consolar a los oyentes o los lectores; y la poética, que exalta el arte como forma de superarlos o trascenderlos.

Con todo, la escritura de los poemas de vanitas se revela como una interesante conjunción de texto e imagen, que involucra numerosos aspectos y dimensiones, $\mathrm{y}$ que pone en evidencia, una vez más, la riqueza y la complejidad de las manifestaciones interartísticas.

79 Ramos 2008, op. cit. (nota 40), p. 452. 